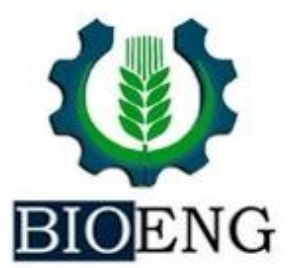

\title{
CARACTERÍSTICAS FÍSICAS E DE EMERGÊNCIA DE SEMENTES DE Cordia trichotoma (VELL.) ARRAB. EX STEUD) ARMAZENADAS EM CONDIÇÃO AMBIENTE
}

\author{
C. R. B. Maffra*
}

UFSM - Universidade Federal de Santa Maria, Santa Maria, RS, Brasil.

Article history: Received 04 March 2019; Received in revised form 06 May 2019; Accepted 22 May 2019; Available online 24 June 2019.

\section{RESUMO}

O presente trabalho teve por objetivo determinar as características físicas e de emergência de sementes de louro-pardo (Cordia trichotoma (Vell.) Arrab. Ex Steud) armazenadas em condição ambiente. As sementes utilizadas no experimento foram coletadas de seis árvores matrizes e armazenadas por 120 dias. Decorrido este período, realizou-se a caracterização dos aspectos físicos e de emergência das sementes de cada árvore matriz conforme as Regras de Análises de Sementes. Os testes realizados foram: peso de mil sementes; número de sementes/kg; teor de umidade; emergência e IVG. Em média, obteve-se peso de mil sementes de $31,25 \mathrm{~g}$, número de sementes por quilograma de 32.557 e teor de umidade de $11,91 \%$. Quanto à emergência e IVG, seus valores médios foram $1,56 \%$ e 0,45 respectivamente. As matrizes de louro-pardo apresentam diferença quanto ao potencial de emergência, sendo que o período de armazenamento de 120 dias em condição ambiente reduz drasticamente a viabilidade das sementes.

Palavras-chave: espécie nativa, longevidade de sementes, perda de viabilidade.

\section{PHYSICAL AND EMERGENCY CHARACTERISTICS OF SEEDS OF Cordia trichotoma (VELL.) ARRAB. EX STEUD STORED IN AMBIENT CONDITION}

\begin{abstract}
This study aimed to determine the physical and emergency characteristics of seeds of louropardo (Cordia trichotoma (Vell.) Arrab. Ex Steud) stored in ambient condition. The seeds used in the experiment were collected from six mother trees, stored for 120 days. After this period, the characterization of the physical and emergency aspects of the seeds of each mother tree was carried out according to the Rules of Seeds Analysis. The tests performed were: weight of one thousand seeds, number of seeds $/ \mathrm{kg}$, moisture content, emergency and GRI. On average, weight of one thousand seeds $31.25 \mathrm{~g}$, number of seeds $/ \mathrm{kg}$ of $32,557 \mathrm{~kg}$ and moisture content of $11.91 \%$ were obtained. Regarding the emergency and GRI, their average values were $1.56 \%$ and 0.45 respectively. The Cordia trichotoma mother trees present a difference in the emergence potential, and the storage period of 120 days in ambient condition dramatically reduces seed viability.
\end{abstract}

Keywords: native species, longevity of seed, viability loss

*charles.mafra@hotmail.com 


\section{INTRODUÇÃO}

O louro-pardo (Cordia trichotoma (Vell.) Arrab. ex Steud) pertencente à família Boraginaceae, trata-se de uma espécie secundária inicial, com tendência a pioneira. Apresenta ampla distribuição geográfica no Brasil, ocorrendo desde o estado do Ceará até o Rio Grande do Sul (CARVALHO, 2003). Conforme Reitz et. al. (1983), o louro-pardo é uma das árvores mais típicas, sobretudo da Floresta Estacional Decidual na Região do Alto Uruguai - RS, onde pode atingir de 25 até $35 \mathrm{~m}$ de altura e até $100 \mathrm{~cm}$ de diâmetro a altura do peito.

A espécie apresenta qualidades ornamentais e pode ser utilizada no paisagismo em geral, além disso, é recomendada para reflorestamentos heterogêneos destinados à recomposição de áreas de preservação permanente que foram degradadas. Quanto à sua madeira, esta é amplamente empregada na confecção de móveis, em tornearia de peças, construção de embarcações, tonéis, caixilhos, entre outros (LORENZI, 1998).

Quanto à qualidade e comportamento das sementes de louropardo, Mendonça (2001), afirma que muito pouco ainda se conhece e que a realização de maiores estudos neste sentido é de fundamental importância, pois 0 aproveitamento comercial da espécie ainda depende predominantemente da exploração predatória das florestas onde ela ocorre. Araldi et al., (2008), ressalta a grande importância da espécie e afirma que a necessidade de estudos que identifiquem as melhores árvores matrizes quanto à produção de sementes são indispensáveis quando o intuito é potencializar a produção de mudas.

\section{MATERIAL E MÉTODOS}

As sementes de louro pardo (Cordia trichotoma) foram coletadas separadamente de seis árvores matrizes, localizadas em diferentes fragmentos de Floresta Estacional Decidual no município de Frederico Westphalen - RS, Brasil.
Neste contexto, dentre os problemas silviculturais inerentes à espécie, pode-se destacar uma possível perda acelerada da viabilidade de suas sementes quando armazenadas em condições ambientes (apenas acondicionadas em sacos plásticos e colocadas à sombra), uma vez que as mesmas são classificadas como recalcitrantes (MARCHETTI, 1984; CARVALHO, 2003). Segundo Bonner (1989), para sementes recalcitrantes, a redução do teor de umidade é crítica para a conservação de sua viabilidade.

Kano et al., (1978), comenta que no armazenamento em ambiente, a umidade presente no ar pode ser suficiente para promover o reinicio das atividades do embrião, isto se o oxigênio e a temperatura forem suficientes. Assim, a respiração consome parte das reservas da semente transformando-as em substâncias mais simples, o que juntamente com a ação dos microrganismos, provoca o aquecimento das sementes e, consequentemente, pode reduzir drasticamente sua viabilidade.

Assim, a capacidade e a qualidade germinativa das sementes estão diretamente associadas à maneira com que estas são armazenadas, onde a forma de armazenamento escolhida, seja ela em ambiente controlado ou não, poderá repercutir diretamente na qualidade e na quantidade de mudas produzidas da espécie em questão. Frente a isso, o presente estudo buscou descrever o comportamento físico e de emergência das sementes de louro-pardo armazenadas sob condição ambiente.

Após coletadas as sementes foram acondicionadas separadamente em sacos plásticos e mantidas à sombra, em condições de temperatura ambiente $\left( \pm 25^{\circ} \mathrm{C}\right)$, por 120 dias. 
Os testes laboratoriais para a caracterização dos aspectos físicos e de emergência das sementes foram realizados no Laboratório de Silvicultura (LASIL) e no Viveiro Florestal da Universidade Federal de Santa Maria, campus de Frederico Westphalen, RS.

\section{Caracterização física das sementes}

Para a caracterização física dos lotes de sementes, os testes descritos a seguir foram realizados seguindo os padrões descritos nas Regras de Análise de Sementes - RAS (Brasil, 2009).

\section{a) peso de mil sementes}

Foram utilizadas oito amostras de 100 sementes, das quais foram calculados a variância $\left(\mathrm{S}^{2}\right)$, o desvio padrão $(\mathrm{S})$ e o coeficiente de variação (CV\%). O peso de mil sementes foi obtido pela fórmula a seguir:

Peso de mil sementes $=\frac{\text { peso da amostra }}{n^{\circ} \text { total de sementes }}$

\section{b) número de sementes por quilograma}

Obtido através do cálculo regra de três a partir do resultado encontrado para o peso de mil sementes.

$$
\begin{aligned}
& 1000 \text { sementes }--- \text { x gramas } \\
& \text { x sementes }---1000 \text { gramas }
\end{aligned}
$$

\section{c) teor de umidade}

Para cada lote foram utilizadas 4 repetições de 25 sementes, onde cada repetição foi pesada inicialmente em condição úmida e logo após levadas até estufa de secagem sob temperatura de $105 \pm 3^{\circ} \mathrm{C}$ durante 24 horas. A determinação do teor de umidade foi realizada através da fórmula a seguir:

$$
\text { Teor de umidade }(\%)=\frac{100(\mathrm{P}-\mathrm{p})}{\mathrm{P}-\mathrm{t}}
$$

Onde:

$\mathbf{P}=$ peso inicial, peso do recipiente e sua tampa mais o peso da semente úmida; $\mathbf{p}=$ peso final, peso do recipiente e sua tampa mais o peso da semente seca; $\mathbf{t}=$ tara, peso do recipiente com sua tampa.

\section{Caracterização da emergência das sementes}

Para cada matriz foram semeadas quatro repetições de 50 sementes, perfazendo o total de 200 sementes, conforme parâmetros das Regras de Análise de Sementes - RAS (Brasil, 2009). $\mathrm{O}$ teste de emergência foi conduzido sob condições de casa de vegetação, em tubetes preenchidos com substrato comercial e acomodados sobre bandejas plásticas.

As avaliações de emergência foram efetuadas cada 2 dias até o término do período de emergência $\left(37^{\circ}\right.$ dia após semeadura), sendo consideradas emergidas aquelas sementes que expunham os cotilédones acima do nível do substrato.

A partir dos resultados foi determinado o seguinte:

\section{a) índice de velocidade de germinação (IVG)}

Teste de vigor, calculado através da fórmula apresentada por Maguire (1962). Índice que descreve o quão rápida é a germinação.

$$
\mathrm{IVG}=\frac{\mathrm{G} 1}{\mathrm{~N} 1}+\frac{\mathrm{G} 2}{\mathrm{~N} 2}+\ldots+\frac{\mathrm{Gn}}{\mathrm{Nn}}
$$

Onde:

G1, G2 e Gn = número de sementes germinadas computadas na primeira, na segunda e na última contagem;

N1, N2 e $\mathbf{N n}=$ número de dias de semeadura na primeira, segunda e última contagem.

\section{b) germinação final (GF)}

Corresponde a porcentagem total de sementes germinadas contabilizadas no último dia de germinação, determinado através do cálculo regra de três (BRASIL, 2009). Os valores em porcentagem foram transformados em $\operatorname{arc} \operatorname{sen} \sqrt{\mathrm{x}} / 100$ para fins de análise estatística. 


\section{Análise estatística}

O delineamento estatístico utilizado foi o inteiramente casualizado. As médias do IVG e da germinação foram

\section{RESULTADOS E DISCUSSÃO}

Na Tabela 1 são apresentados os resultados dos testes de caracterização física das sementes. Quanto ao peso de mil sementes, os valores variaram entre as matrizes de $25,3 \mathrm{~g}$ a $38,7 \mathrm{~g}$, obtendo como média geral $31,25 \mathrm{~g}$, sendo que os coeficientes de variação ficaram entre 1,16 e 2,99, enquadrando-se abaixo de $4 \%$, conforme recomendações das Regras de Análise de Sementes, descritas em Brasil (2009). Estes resultados, concordam com Araldi et al., (2008), que em trabalho com sementes de louro-pardo no Rio Grande do $\mathrm{Sul}$, encontrou valor médio de $29 \mathrm{~g}$. O número médio de sementes/kg foi de 32.557 sementes, estando dentro da amplitude citada por Carvalho (2003), que pode variar de 20.000 a 37.347 semente/kg. Dentre as matrizes a amplitude de variação foi de 25.839 a 39.525 sementes. Para Araldi et al. (2008), a variação foi de 29.755 a 45.249 sementes/kg, diferença de amplitude que pode estar relacionada ao teor de umidade das sementes no momento em que foram realizados os testes.

Os resultados de teor de umidade das sementes demonstraram-se bastante homogêneos entre matrizes, variando de $10,49 \%$ a $12,71 \%$. Considerando a afirmação de Carvalho (2003), na qual cita que a amplitude ideal do teor de umidade para a colheita das sementes é de $9 \%$ a $13 \%$, os valores obtidos estariam perfeitos. A média obtida do teor de umidade foi de $11,86 \%$, este baixo valor deve-se aos 120 dias de armazenamento, nos quais as sementes desidrataram paulatinamente, o que fica evidente quando os valores são comparadas entre si pelo Teste de Tukey a 5\% de probabilidade de erro, utilizando o software estatístico Statistical Analysis System (SAS).

comparados com o teor de umidade médio das sementes obtido no dia da coleta, o qual foi de 43,19\%. A umidade das sementes no dia da coleta é confirmada pela afirmativa de Castro \& Hilhorst (2004), na qual expressam que as sementes do tipo recalcitrantes, como as do louropardo, não passam pela fase de secagem ao final da maturação, sendo dispersas da planta mãe com teor de umidade relativamente alto. Bonner (2001), afirma que esse tipo de semente não pode ser desidratada a teores de umidade abaixo de 25 a $50 \%$ sem perder a viabilidade, ou seja, a capacidade de germinar ou emergir.

$\mathrm{Na}$ Tabela 2 são expressos os resultados de emergência e IVG. Onde destaca-se a matriz 4, a qual apresentou maior porcentagem de emergência com o valor de $4,5 \%$, diferindo estatisticamente das matrizes 2,3 e 6 . Quanto ao IVG individual, nenhuma das matrizes apresentou diferença significativa entre si. Com relação aos resultados médios de emergência e IVG, estes foram respectivamente de $1,56 \%$ e 0,45 , os quais demonstraram-se baixos devido à perda de viabilidade das sementes em função do longo período de armazenamento sob condição ambiente. Estes resultados estão de acordo com Marchetti (1984), o qual descreve que as sementes de louro-pardo perdem muito rápido a viabilidade quando armazenadas, devendo estas serem semeadas imediatamente após a coleta nas árvores matrizes. Os aspectos gerais da emergência e germinação de sementes de C. trichotoma podem ser observados na Figura 1. 
Tabela 1. Caracterização física de sementes de Cordia trichotoma armazenadas em condição ambiente.

\begin{tabular}{|c|c|c|c|c|c|c|c|c|c|}
\hline \multirow[b]{2}{*}{ Matrizes } & \multicolumn{4}{|c|}{ Peso de mil sementes (g) } & \multirow[b]{2}{*}{$\begin{array}{c}N^{\circ} \text { de } \\
\text { sementes/kg }\end{array}$} & \multicolumn{4}{|c|}{ Teor de Umidade (\%) } \\
\hline & Média & $\mathbf{S}^{2}$ & $\mathbf{S}$ & $\begin{array}{l}\text { CV } \\
(\%)\end{array}$ & & Média & $\mathbf{S}^{2}$ & $\mathbf{S}$ & $\begin{array}{l}\text { CV } \\
(\%)\end{array}$ \\
\hline 1 & 33,1 & 0,0098 & 0,0990 & 2,99 & 30.211 & 12,06 & 2,1168 & 1,4549 & 12,06 \\
\hline 2 & 31,1 & 0,0041 & 0,0640 & 2,06 & 32.154 & 11,17 & 2,0539 & 1,4331 & 12,83 \\
\hline 3 & 25,3 & 0,0050 & 0,0707 & 2,79 & 39.525 & 12,71 & 0,3313 & 0,5756 & 4,53 \\
\hline 4 & 31,1 & 0,0013 & 0,0361 & 1,16 & 32.154 & 12,62 & 8,167 & 2,8578 & 22,65 \\
\hline 5 & 38,7 & 0,0092 & 0,0959 & 2,48 & 25.839 & 10,49 & 0,9836 & 0,9917 & 9,45 \\
\hline 6 & 28,2 & 0,0020 & 0,0447 & 1,56 & 35.460 & 12,13 & 1,7526 & 1,3238 & 10,91 \\
\hline $\begin{array}{l}\text { Média } \\
\text { Geral }\end{array}$ & 31,25 & 0,0052 & 0,0684 & 2,17 & 32.557 & 11,86 & 2,5675 & 1,4395 & 12,07 \\
\hline
\end{tabular}

Tabela 2. Emergência e Índice de Velocidade de Emergência (IVG) de sementes de Cordia trichotoma armazenadas em condição ambiente.

\begin{tabular}{ccc}
\hline & \multicolumn{2}{c}{ Testes } \\
\cline { 2 - 3 } Matrizes & Emergência (\%) & IVG \\
\hline $\mathbf{1}$ & $1,37 \mathrm{abc}$ & $0,28 \mathrm{a}$ \\
$\mathbf{2}$ & $1,12 \mathrm{bcd}$ & $0,25 \mathrm{a}$ \\
$\mathbf{3}$ & $0,00 \mathrm{~d}$ & $0,00 \mathrm{a}$ \\
$\mathbf{4}$ & $4,50 \mathrm{a}$ & $1,54 \mathrm{a}$ \\
$\mathbf{5}$ & $2,25 \mathrm{ab}$ & $0,60 \mathrm{a}$ \\
$\mathbf{6}$ & $0,12 \mathrm{~cd}$ & $0,02 \mathrm{a}$ \\
\hline Média & $\mathbf{1 , 5 6}$ & $\mathbf{0 , 4 5}$ \\
\hline
\end{tabular}

*Médias seguidas de mesmas letras não diferem estatisticamente entre si pelo Teste de Tukey $(\mathrm{p}<0,05)$. 

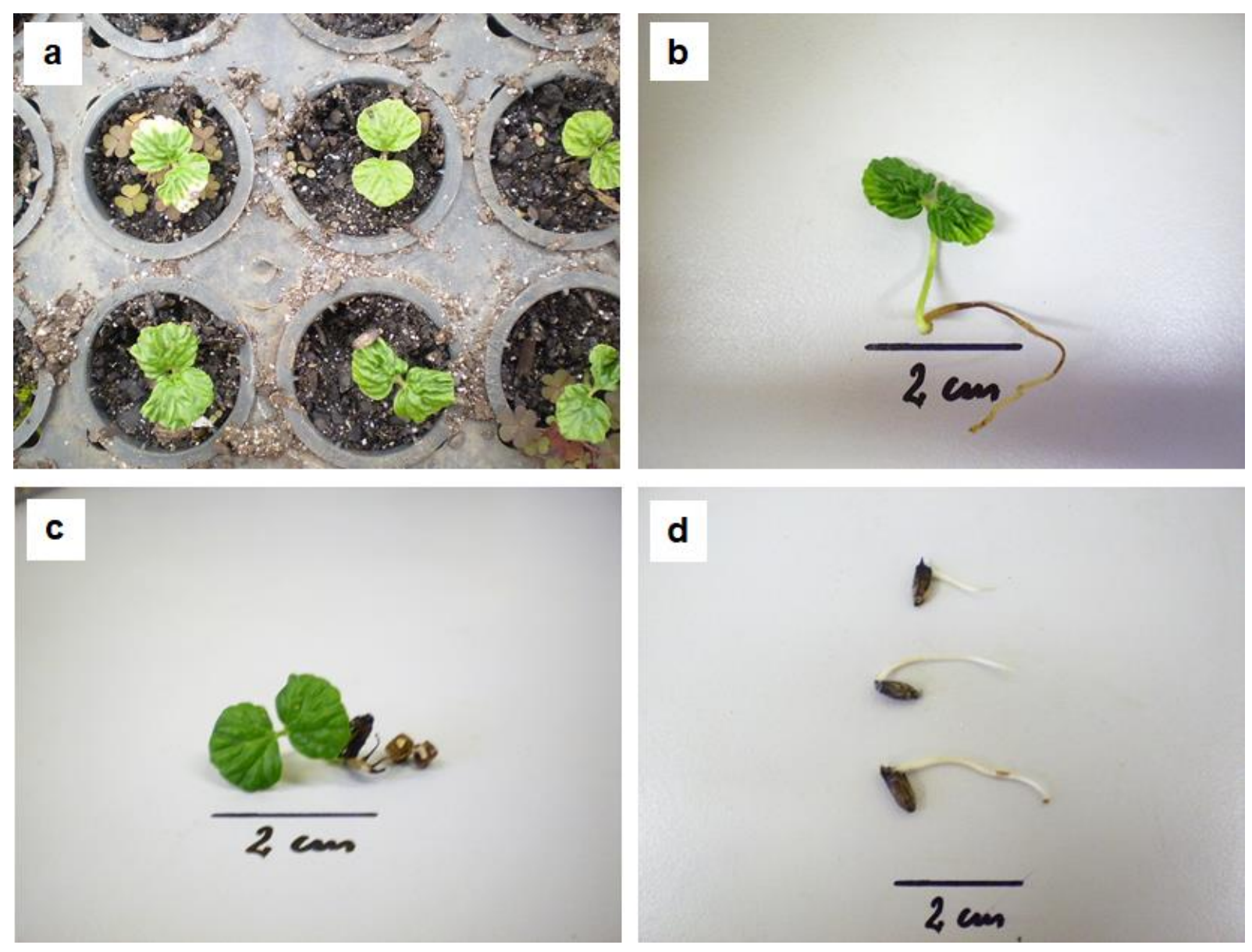

Figura 1. Aspecto geral da emergência (a, b, c) e geminação (d) de sementes da espécie Cordia trichotoma, armazenadas em condição ambiente. Fonte: O Autor.

Considerando-se que as sementes foram armazenadas em condições com temperatura média de $25^{\circ} \mathrm{C}$ e umidade relativa do ar bastante variável (não controlada), evidencia-se que o ambiente em questão se apresentou propício a aceleração da taxa respiratória das sementes. Esta respiração acelerada promove a hidrólise dos carboidratos, os quais são importantes para desencadear os processos de germinação e para suprir as demandas do embrião. Harrington (1972), afirma que se as sementes forem mantidas a baixa temperatura, ocorrerá redução da atividade das enzimas envolvidas no processo respiratório, sendo este, o

\section{CONCLUSÃO}

As sementes de Cordia trichotoma apresentam em média para o peso de mil sementes $31,25 \mathrm{~g} \quad(32.557 \quad$ sementes $/ \mathrm{kg})$ com teor de umidade de $11,86 \%$. principal responsável pela perda da viabilidade das sementes durante 0 armazenamento. Hartmann \& Kester (1974), consideram que as condições efetivas para o armazenamento de sementes compreendem uma combinação de umidade relativa de 10 a $50 \%$ e uma temperatura de 0 a $10^{\circ} \mathrm{C}$. Os resultados concordam com estudos realizados com outras espécies florestais, como Figliolia (1988), que em trabalho com Cedrela fissilis armazenadas em ambiente, com teor de umidade inicial de $12,4 \%$, verificou que aos 60 dias de armazenamento as sementes apresentavam queda de sua viabilidade, de 60 para $3 \%$ de germinação. Existem diferenças entre as
matrizes de louro-pardo, quanto ao
potencial de emergência das sementes,
sendo que o período de armazenamento de 
120 dias em condição ambiente reduz drasticamente a viabilidade das sementes da espécie.

\section{REFERÊNCIAS}

ARALDI, D. B.; COSTA, E. C.; ARAÚJO, M. M.; SOUZA, D.; TREVISAN, R. Fenologia, seleção de árvores matrizes e coleta de sementes de Cordia trichotoma (Vell.) Arrab. ex Steud. no Rio Grande do Sul, Brasil.. In: $5^{\circ}$ SIMPÓSIO DE PÓS-GRADUAÇÃO EM CIÊNCIAS FLORESTAIS, BRASÍLIA 14-16 agost, 2008, Brasília. Anais do 5. Simpósio de Pós-Gtraduação em Ciências Florestais. Brasíla: José Imañas-Encinas, 2008. p. 879-890.

BONNER, F. T. Seed Biology. In: Woody-Plant Seed Manual. (s.1.): USDA Forest Service's/Reforestation, Nurseries, \& Genetics Resources, 2001.

BONNER, F. T. Tropical forest seeds: biology, quality and technology. In: Simpósio Brasileiro sobre Sementes Florestais, 2., 1989, Atibaia, SP. Anais... Atibaia, São Paulo: SEMASP/IF, 1989. p.263-274.

BRASIL. Ministério da Agricultura, Pecuária e Abastecimento. Regras para análise de sementes. Brasília: MAPA/ACS, 399 p., 2009.

CARVALHO, P. E. R. Espécies arbóreas brasileiras. v.1 Brasília: Embrapa Informação Tecnológica; Colombo/PR: Embrapa Florestas,. 1039 p., 2003.

CARVALHO, P. E. R. Espécies florestais brasileiras: recomendações silviculturais, potencialidades e usos da madeira. Colombo, Empresa Brasileira de Pesquisa Agropecuária, Centro Nacional de Pesquisa de Florestas, 640 p., 1994.

CASTRO, R. D.; HILHORST, H. W. M. Embebição e reativação do metabolismo. Pp.149-162. In: A.G. Ferreira \& F.
Aconselha-se que as sementes de $C$. trichotoma sejam plantadas logo após a coleta nas árvores matrizes.

Borghetti (eds.). Germinação: do básico ao aplicado. Porto Alegre, Artmed, 2004.

FIGLIOLIA, M.B. 1988. Conservação de sementes de essências florestais. Boletim Técnico IF, São Paulo, 43:1-18, 1988.

HARRINGTON, J. F. Seed storage and longevity. In: KOSLOWSKI, T. T. - Seed biology. New York, Academic Press, v. 3, p.145-245, 1972.

HARTMANN, H. T.; KESTER, D. E. Propagación de plantas. México, Continental, 810 p, 1974.

KANO, N. K.; MARQUEZ, F. C. M.; KAGEYAMA, P. Y. Armazenamento de sementes de ipê-dourado (Tabebuia $s p$ ). IPEF n.17, p.13-23, 1978.

LORENZI, H. Árvores brasileiras: manual de identificação de plantas arbóreas nativas do Brasil. 2.ed. São Paulo: Editora Plantarum, 368 p., 1998.

MAGUIRE, J. D. Speed of germinationaid in selection and evaluation for seedling emergence and vigor. Crop Science, Madison, v. 2, n. 1, p. 176-177, 1962.

MARCHETTI, E. R. Época de coleta, semeadura, tratamento pré-germinativo e métodos de semeadura de espécies florestais cultivadas no Rio Grande do Sul. In: CONGRESSO FLORESTAL ESTADUAL, 5, Nova Prata, 1984. Anais. Nova Prata: Prefeitura Municipal, v.2, p.524-532, 1984.

MENDONÇA, E. A. F.; RAMOS, N. P.; PAULA, R. C. Viabilidade de sementes de Cordia trichotoma (Vellozo) Arrabida ex Steudel (louro-pardo) pelo teste de tetrazólio. Revista Brasileira de 
Sementes, Brasília, v. 23, n. 2, p. 64-71, 2001.

PEDROSO, O.; MATTOS, J. R. Estudo sobre madeiras do Rio Grande do Sul.

Porto Alegre: Instituto de Pesquisas de
Recursos Naturais Renováveis Ataliba Paz, 181 p., 1987.

REITZ, R., KLEIN, R. M., REIS, A. Projeto madeira do Rio Grande do Sul. Porto Alegre: Secretaria de Agricultura e Abastecimento, 524 p., 1983. 